\title{
Collating the knowledge base for the COMET (core outcome measures in effectiveness trials) initiative - a systematic review
}

\author{
Elizabeth Gargon*, Binu Gurung, Paula Williamson \\ From 2nd Clinical Trials Methodology Conference: Methodology Matters \\ Edinburgh, UK. 18-19 November 2013
}

\section{Background}

The COMET Initiative is developing a publically-accessible online resource to collate the knowledge base for core outcome set (COS) development and implementation. This will be used by trial funders, trialists and researchers to see what has been done in their area of interest, and by research funders wishing to fund new work in this area who want to avoid unnecessary duplication of effort. This requires the development and application of an optimal, multi-faceted search strategy to identify work related to the development of COS.

\section{Objectives}

To identify studies that had the aim of determining which outcomes or domains to measure in all clinical trials in a specific condition, and to identify and describe the methodological techniques used in these studies.

\section{Methods}

We developed a multi-faceted search strategy to search electronic databases (MEDLINE via Ovid, SCOPUS and the Cochrane Methodology Register). We contacted Cochrane Review Groups across all areas of health care to request information on COS that they are aware of. We also completed a range of hand searching activities.

\section{Results}

Databases were searched in August 2012 for studies of the selection of outcomes for use in clinical trials. The search identified 24804 potentially relevant abstracts. Screening is ongoing to identify the final set of included studies; it is expected this work will be completed in September 2013. Pilot work suggests that an estimate of

University of Liverpool, Liverpool, UK

C 2013 Gargon et al; licensee BioMed Central Ltd. This is an Open Access article distributed under the terms of the Creative Commons Attribution License (http://creativecommons.org/licenses/by/2.0), which permits unrestricted use, distribution, and reproduction in any medium, provided the original work is properly cited. be presented.

\section{Conclusions}

This systematic review has identified clinical areas where work has been undertaken, providing the knowledge base for COS development. This review also highlights clinical areas where gaps exist, providing opportunities for future COS development. This is the first step in establishing a database of COS. Ensuring that the database is as comprehensive as possible and keeping it up to date are key to its value for users.

Published: 29 November 2013

doi:10.1186/1745-6215-14-S1-067

Cite this article as: Gargon et al:: Collating the knowledge base for the COMET (core outcome measures in effectiveness trials) initiative - a systematic review. Trials 2013 14(Suppl 1):O67.

Submit your next manuscript to BioMed Central and take full advantage of:

- Convenient online submission

- Thorough peer review

- No space constraints or color figure charges

- Immediate publication on acceptance

- Inclusion in PubMed, CAS, Scopus and Google Scholar

- Research which is freely available for redistribution up to 1200 relevant papers will be included. Results will 